\title{
Pregnancy in Diabetics: Clinicobiological Features and Evolution
}

\author{
Y.Htira, M.Belhadj, Z.Hadj Ali, and F.Ben Mami
}

\section{ABSTRACT}

Background: The association between diabetes and pregnancy is a real public health problem due to the inherent maternal and fetal complications.

Aims: To study the clinical and biological features of diabetic pregnancies.

Methods: We conducted a retrospective descriptive study including pregnant diabetic women followed at the National Institute of Nutrition of Tunis.

Results: We included 100 patients with a mean age of $32.87 \pm 5.3$ years. In preconception, $63.6 \%$ of patients were overweight and had poorly balanced diabetes (HbA1c> 7\%). The mean weight gain throughout the pregnancy was $8.62 \pm 5.39 \mathrm{~kg}$. Pregnancy was planned in $18 \%$ of cases.

Significant improvement in HbA1c was observed in the second trimester. The average daily insulin dose increased from $0.68 \mathrm{u} / \mathrm{kg} / \mathrm{day}$ in the first trimester to $0.87 \mathrm{u} / \mathrm{kg} / \mathrm{day}$ in the third trimester $(\mathrm{p}<0.001)$. Full term delivery occurred in $72 \%$ of cases.

The majority $(93.3 \%)$ of our patients gave birth by caesarean section. Macrosomia was observed in $24 \%$ of cases. The main neonatal complications were neonatal respiratory distress and hypoglycemia in $26.7 \%$ and $20.5 \%$ of cases, respectively. Five newborns had deformities.

Conclusion: Diabetic pregnancy is associated with an increased risk of maternal and fetal complications. An action on modifiable factors, before conception, could significantly improve its prognosis.

Keywords: Complications, diabetes, insulin, pregnancy.

Submitted: July 1, 2021

Published: August 17, 2021

ISSN: 2593-8339

DOI: $10.24018 /$ ejmed.2021.3.4.975

Y.Htira*

Institut National de Nutrition et de Technologies Alimentaires, Tunisia.

(e-mail: yosrahtira@gmail.com)

M.Belhadj

Institut National de Nutrition et de

Technologies Alimentaires, Tunisia.

(e-mail: mahabelhadj1006@ ${ }^{@ m a i l . c o m) ~}$

Z.Hadj Ali

Institut National de Nutrition et de

Technologies Alimentaires, Tunisia.

(e-mail: hadjalinbz@ ${ }^{@ m a i l . c o m) ~}$

F. Ben Mami

Institut National de Nutrition et de

Technologies Alimentaires, Tunisia.

(e-mail : benmamifaika@yahoo.fr)

*Corresponding Author

\section{INTRODUCTION}

The combination of diabetes and pregnancy is very common. This is a high-risk pregnancy: pregnancy unbalances diabetes, at the same time, diabetes darkens the prognosis of the mother and the fetus. Close management and rigorous multidisciplinary monitoring by the diabetologist and obstetrician during pregnancy, but especially in preconception, are therefore essential to limit complications, hence the importance of planning pregnancy.

\section{AIMS}

The aim of this study was to assess glycemic control before, during and after pregnancy as well as maternal and fetal complications in pregnant diabetic women.

\section{METHODS}

We carried out a retrospective descriptive study including pregnant diabetic women, recruited from the patients followed at the National Institute of Nutrition of Tunis (INNT).
We included pregnant women with type 1 or type 2 diabetes who received regular metabolic monitoring throughout pregnancy.

The data was collected from the clinical records of patients hospitalized at the INNT. The missing data were obtained by telephone contact of the patients.

All the patients had undergone an interrogatory and a complete physical examination which included anthropometric and blood pressure measurements. The World Health Organization (WHO) classification [1] was used to assess the nutritional status of patients before pregnancy. To calculate the excess weight gain in our patients, we used French recommendations for weight gain during pregnancy according to the pre-gestational Body Mass Index (BMI) class [2]. We referred to the guidelines of the American Thyroid Association (ATA) 2017 [3] to interpretate the thyroid tests with the following standards

$\mathrm{TSH}<2.5 \mathrm{~m} \mathrm{IU} / 1$ in the first trimester and TSH $<3 \mathrm{~m} \mathrm{IU} \mathrm{/}$ 1 in the second and in the third trimester.

We studied the following parameters: pregnancy planning; the aim was a preconceptional glycated hemoglobin (HbA1c) of less than $6.5 \%$ according to the guidelines of the American Diabetes Association (ADA) 2020 [4], glycemic control during pregnancy, any obstetric complications, the mode and 
term of delivery, the reason for the cesarean section, the birth weight as well as neonatal complications.

Postpartum, we collected data about treatment of diabetes and glycemic control.

There were no conflicts of interest for our study.

All the patients participating in this work were informed about the aims and methods of the study. Informed consent was taken beforehand.

\section{RESULTS}

We included 100 patients. The mean age was $32.87 \pm 5.3$ years. The majority of patients had a secondary education level. The mean pre-gestational BMI was $28.2 \pm 6.48 \mathrm{~kg} / \mathrm{m}^{2}$. More than half of the patients had type 2 diabetes (52\%), the others had type 1 diabetes. The mean duration of diabetes was $7.57 \pm 6.66$ years. The majority of our patients $(62.2 \%)$ were already on insulin therapy before conception. The mean weight gain throughout the pregnancy was $8.62 \pm 5.39 \mathrm{~kg}$. The average of weight gain and the frequency of excessive weight gain is detailed in Table I.

TABLE I: AVERAGE OF WEIGHT GAIN AND FREQUENCY OF EXCESSIVE WEIGHT GAIN ACCORDING TO BMI CLASS IN 100 TUNISIAN PREGNANT

\begin{tabular}{cccc}
\multicolumn{4}{c}{ DIABETICS } \\
\hline $\begin{array}{c}\text { Pregestational BMI } \\
\left(\mathrm{kg} / \mathrm{m}^{2}\right)\end{array}$ & Normal & $(25,29.9)$ & $\geq 30$ \\
\hline $\begin{array}{c}\text { Mean weight gain }(\mathrm{Kg}) \\
\begin{array}{c}\text { Frequency of excessive } \\
\text { weight gain }(\%)\end{array}\end{array}$ & $7.24 \pm 11.75$ & $10.71 \pm 5.59$ & $5.1 \pm 5.09$ \\
\hline
\end{tabular}

The majority of our patients $(70 \%)$ had poorly balanced preconception diabetes (HbA1c>7\%).

Three quarters of the patients included in our study consulted in diabetology before the 8th week of amenorrhea (WA). Only $18 \%$ of patients had planned their pregnancies.

All our patients were followed by gynecologists.

Regarding the treatment of diabetes during pregnancy, all of our patients were on insulin from the 12th WA. Insulin was introduced at an average of $3.11 \pm 4.16$ weeks.

The majority $(90.4 \%)$ of our patients had a glucometer.

The monitoring of diabetes was performed several times per month, several times per week or daily in 5.5, 39.6 and 54.9 $\%$ of cases, respectively.

With regard to glycemic control, the mean and extreme values of $\mathrm{HbA} 1 \mathrm{c}$ in the first trimester (T1), second trimester (T2) and third trimester (T3) were respectively $8.12 \pm 1.55 \%$ $(4,8-12.9 \%), 6.69 \pm 1.03 \%(4.5-10.4 \%)$ and $6.86 \pm 1.27 \%$ (4.8$12.8 \%)$.

The mean daily insulin dose at T1, T2 and T3 were 0.68 , 0.74 and $0.87 \mathrm{IU} / \mathrm{kg} / \mathrm{d}$, respectively.

Metabolic complications during pregnancy were hypoglycemia and ketosis. The frequencies of these complications at T1, T2 and T3 are shown in Fig. 1.

Regarding microvascular complications, no patient worsened her retinopathy throughout pregnancy. Patients with microalbuminuria early in pregnancy have not developed macroalbuminuria. Only one patient had macroalbuminuria at the beginning of pregnancy, which remained stable throughout the pregnancy (proteinuria at T1 $=1 \mathrm{~g} / 24 \mathrm{~h}$; at T2 = $1.96 \mathrm{~g} / 24 \mathrm{~h}$; at T3 = $680 \mathrm{mg} / 24 \mathrm{~h})$.

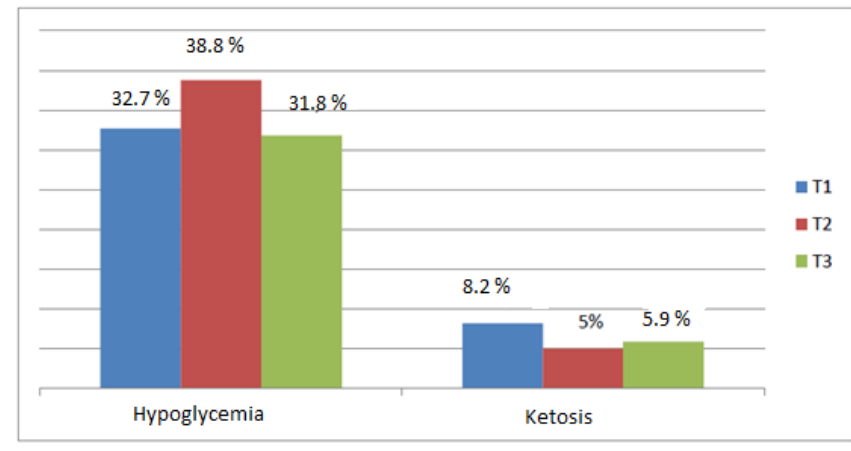

Fig.1. Frequency of metabolic complications as a function of the term of pregnancy in 100 Tunisian pregnant diabetics.

$\mathrm{T} 1=$ first trimester; $\mathrm{T} 2=$ second trimester; $\mathrm{T} 3=$ third trimester.

Regarding the thyroid function, 13 of the patients already had hypothyroidism and were on hormone replacement therapy before pregnancy. No case of hyperthyroidism was noted. Eight cases of hypothyroidism were diagnosed during pregnancy. At the end of the pregnancy, $21.6 \%$ of the patients were on hormone replacement therapy.

In addition, $10 \%$ of patients had a medical history of anemia. During pregnancy, microcytic anemia was observed in $8 \%$ of patients at T1, $4 \%$ of patients at $\mathrm{T} 2$ and in $12 \%$ of patients at T3. A statistically significant decrease in hemoglobin level at T3 compared to T1 was observed ( $\mathrm{p}$ $<0.001)$.

At the end of the pregnancy, $76 \%$ of the women were on iron treatment.

During pregnancy, $46 \%$ of patients had at least one obstetrical complication. They are shown in Table II.

TABLE II: COMPLICATIONS OCCURRING DURING PREGNANCY IN 100 TABLE II: COMPLICATIONS OCCURRING DURING PREIST
TUNISIAN PREGNANT DIABETICS

\begin{tabular}{ccc}
\hline Complication & Number & Frequency $(\%)$ \\
\hline Cystitis & 19 & 22.6 \\
Preterm labor & 16 & 21.6 \\
Hypertension & 10 & 11.2 \\
Preeclampsia & $\mathbf{2}$ & $\mathbf{2 . 1}$ \\
\hline
\end{tabular}

The mean delivery term was $37.47 \pm 1.75$ weeks. The pregnancies outcome is shown in Table III.

TABLE III: OUTCOME OF THE PREGNANCIES IN 100 TUNISIAN PREGNANT

\begin{tabular}{ccc}
\multicolumn{3}{c}{ DIABETICS } \\
\hline Outcome of pregnancy & Number & Frequency $(\%)$ \\
\hline At term delivery & 72 & 72 \\
Preterm delivery & 15 & 15 \\
Early abortion & 8 & 8 \\
Late abortion & 1 & 1 \\
Fetal death in utero & 3 & 3 \\
Termination of pregnancy & 1 & 1 \\
\hline
\end{tabular}

Only one pregnancy termination was performed due to a polymalfomative syndrome detected on ultrasound examination. The majority $(93.3 \%)$ of our patients gave birth by cesarean section; the main reasons were acute fetal distress (29.6\%), macrosomia (23\%), scarred uterus (18.5\%) and breech presentation $(7.4 \%)$.

The mean birth weight was $3577.2 \pm 0.72 \mathrm{~g}$. More than half of the newborns $(51.7 \%)$ presented at least one neonatal complication, requiring hospitalization in a neonatal unit in $34.9 \%$ of cases. Neonatal complications were neonatal respiratory distress, hypoglycemia, jaundice, materno-fetal infection and hypocalcaemia in 26.7, 20.5, 17.6, 15.3 and 6 
$\%$ of cases, respectively.

Five newborns (5.7\%) presented congenital malformations: three cardiac, one urological and one polymalformative syndrome.

After childbirth, 47 patients came to our consultations; the mean consultation time was $16.8 \pm 6.27$ weeks after delivery.

The mean postpartum HbA1c level was $8.57 \pm 1.84 \%$ with extremes of 5.8 to $13.3 \%$.

\section{DISCUSSION}

Our study is one of the few Tunisian studies that have studied the course of pregnancies in diabetic patients during the gestational period and during the postnatal period. It is now well demonstrated that optimizing the HbA1c level could largely improve the pregnancy outcome.

In our study, a statistically significant improvement in glycemic control at $\mathrm{T} 2$, assessed by the level of HbA1c, was observed. However, there was a slight increase in $\mathrm{HbA1c}$ at T3, with no significant difference $(p=0.21)$.

Likewise, the Fennira study [5] showed similar results with an improvement in the glycemic control at $\mathrm{T} 2$ compared to $\mathrm{T} 1$ (from $8.41 \% \pm 1.91$ to $6.43 \% \pm 1.07$ ). At $\mathrm{T} 3$, HbA1c increased slightly to $6.76 \% \pm 1.52$ compared to $\mathrm{T} 2$.

This improvement in HbA1c levels during pregnancy could be explained by the hemodilution caused by gestation [6], physiological changes in red blood cells: decrease in their lifespan and increase in their number [7], [8], a lower degree of glycation [7] as well as by patient motivation and regular medical monitoring.

Insulin is the only pharmacological treatment of diabetes during pregnancy. Indeed, optimizing insulin doses is essential in reducing complications in diabetic pregnancy [9].

In our study, insulin requirements increased during pregnancy (from $0.68 \mathrm{IU} / \mathrm{kg} / \mathrm{d}$ at $\mathrm{T} 1$, to $0.74 \mathrm{IU} / \mathrm{kg} / \mathrm{d}$ at $\mathrm{T} 2$ and to $0.87 \mathrm{IU} / \mathrm{kg} / \mathrm{d}$ at $\mathrm{T} 3, \mathrm{p}<0.001)$. Our results are comparable to those found in the Sfar study [7] which showed conventional insulin requirements at $\mathrm{T} 3$ of $0.84 \pm 0.29 \mathrm{IU} / \mathrm{kg} /$ day.

In addition, anemia is often associated with pregnancy. In our study, $12 \%$ of pregnant women had anemia. The risk of developing anemia is 2 to 3 times greater in diabetics than in non-diabetics [10]. According to the national nutritional survey carried out by the National Institute of Nutrition of Tunis in 2002, the prevalence of anemia observed in pregnant women was $32.3 \%$ [11].

A statistically significant relationship was found between anemia and poor glycemic control $(p=0.002)$ [10], [12]. The main etiologies of anemia were chronic kidney disease in 44 $\%$ of cases, iron deficiency in $23 \%$ of cases, mixed etiology in $6 \%$ of cases, vitamin B12 deficiency in $2 \%$ of cases and minor thalassemia in $1 \%$ of cases. The authors emphasized the need for systematic screening and optimal control of diabetes [12].

The combination of diabetes and anemia exposes pregnant women and newborns to multiple short and long-term risks [13]. In fact, the alteration of cellular immune defense mechanisms, through iron deficiency, leads to a greater risk of infection in pregnant women. Postpartum hemorrhage from uterine atony is more common in women with anemia due to impaired contraction capacity of the uterine muscle
[13].

Newborns of anemic mothers have a greater risk of cesarean birth, prematurity, intrauterine growth retardation (IUGR) and perinatal mortality [10], [14].

Preeclampsia complicates $2 \%$ of pregnancies [15]. Diabetes and preeclampsia are often closely related. In a meta-analysis including 21 studies, it was proven that women with type 1 or type 2 diabetes are 2 to 4 times more likely to develop preeclampsia during their pregnancies compared to women without diabetes [16]-[18]. In our series, $2.1 \%$ of pregnancies were complicated by preeclampsia. This risk may be increased in women with type 1 diabetes who are overweight [18]. Preeclampsia is one of the main causes of maternal and perinatal morbidity and mortality [16].

On the other hand, a cesarean delivery was necessary in $93.3 \%$ of the cases in our study. This rate is much higher than that reported by other international studies Australian [19] (53.6\%), Irish [20] (type 1 diabetes: 30\%, type 2 diabetes: $36 \%)$ or Emirati [21] (39.1\%).

The significantly high frequency of cesarean sections reported in our work could be explained by the mono-centric nature of the study exposing to a center effect (the patients referred to our Institute often have more complicated diabetes and pregnancies and consequently increased morbidity) and by the fact that $53 \%$ of our patients had no living children therefore their pregnancies were precious.

The main perinatal complications encountered in our work were neonatal respiratory distress (NNRD), hypoglycemia and macrosomia in $26.7 \%, 20.5 \%$ and $24 \%$ of cases, respectively.

A French study [22] including 588 pregnant women with type 1 diabetes and spanning 15 years, tried to identify the determinants of a good perinatal prognosis. A good perinatal prognosis was defined as the uncomplicated delivery of a fullterm infant, not malformed, of normal birth weight, without any neonatal complications. Only $44 \%$ of pregnancies had a good perinatal prognosis (versus $48.3 \%$ in our study according to these criteria).

These results were associated with lower maternal HbA1c values at delivery and the absence of preeclampsia.

NNRD is a common cause of neonatal hospitalization and death in low-income countries, which do not have the optimal means for its management. Preventing NNRD by acting on its risk factors is of considerable importance for countries with limited resources, such as ours. In our study, $26.7 \%$ of newborn had NNRD.

A meta-analysis [23], including 24 studies, showed that maternal diabetes, whether gestational or pregestational, induces a greater risk of NNRD [23], [24].

In our study, $20.5 \%$ of newborns had hypoglycemia. Postnatal hypoglycemia is the main known metabolic complication in newborns of diabetic mothers [25].

Regarding postpartum follow-up, more than half (53\%) of patients followed during pregnancy were lost to follow-up after childbirth. As our Institute is a reference center for the follow-up of diabetic pregnant women, many of these women are referred to our consultations for the follow-up of the pregnancy. After childbirth, some patients return to their primary health institution. 


\section{CONCLUSION}

Diabetic pregnancy is associated with an increased risk of maternal and fetal complications. Preconception management and action on modifiable factors by developing a national educational program focused on diabetic pregnancy, for example, could significantly improve the prognosis of these pregnancies.

\section{REFERENCES}

[1] WHO, Obesity: preventing and managing the global epidemic, Report of a WHO consultation, World Health Organ Tech Rep Ser, 2000;894:ixii, 1-253.

[2] Kuehn BM., Guideline for pregnancy weight gain offers targets for obesewomen,JAMA, 2009;302(3):241-2.

[3] Alexander EK, Pearce EN, Brent GA, Brown RS, Chen H, Dosiou C, et al. 2017, Guidelines of the American Thyroid Association for the Diagnosis and Management of Thyroid Disease During Pregnancy and the Postpartum, Thyroid, 2017;27(3):315-89.

[4] American Diabetes Association. "14. Management of diabetes in pregnancy: Standards of Medical Care in Diabetes-2020", Diabetes Care43, Supplement 1 (2020): S183-S192.

[5] Fennira E. Place de la fructosamine dans le suivi de la grossesse diabétique.Th D Med, Tunis; 2015.

[6] Nielsen LR, Ekbom P, Damm P, Glümer C, Frandsen MM, Jensen DM, et al., HbA1c levels are significantly lower in early and late pregnancy,Diabetes Care, 2004;27(5):1200-1.

[7] Lurie S., Age distribution of erythrocyte population in late pregnancy,GynecolObstet Invest., 1990;30(3):147-9.

[8] Lurie S, Danon D., Life span of erythrocytes in late pregnancy,ObstetGynecol, 1992;80(1):123-6.

[9] Gottlied PA, Frias JP, Petrers KS, Chillara B, Gargs K., Optimizing insulin therapy in pregnant women with type 1 diabetes mellitus, Treat Endocrinol., 2002; 1(4) :235-4.

[10] Sahay M, Kalra S, Badani R, Bantwal G, Bhoraskar A, Das AK, et al., Diabetes and Anemia: International Diabetes Federation (IDF) Southeast Asian Region (SEAR) position statement,Diabetes \& Metabolic Syndrome:Clini Res Rev, 2017;11:S685-95.
[11] Rayana MCB, Kolsteren P, Lefèvre P, Gharbi T, Jaafar SK-B, Beghin I., Approche causale de l'anémie par carence en fer,Optionsmediterrniennes, 2002 (41): 41-49.

[12] Shams N, Osmani MH. Newly diagnosed anemia in admitted diabetics, frequency, etiology and associated factors, J Coll Physicians Surg Pak, 2015;25(4):242-6.

[13] Levy A, Fraser D, Katz M, Mazor M, Sheiner E., Maternal anemia during pregnancy is an independent risk factor for low birthweight and preterm delivery,Eur J ObstetGynecolReprod Biol,2005;122(2):182-6.

[14] Hutcheon JA, Lisonkova S, Joseph KS., Epidemiology of preeclampsia and the other hypertensive disorders of pregnancy,Best Pract Res Clin ObstetGynaecol, 2011;25(4):391-403.

[15] Wotherspoon AC, Young IS, Patterson CC, McCance DR, Holmes VA, Diabetes and Pre-eclampsia Intervention Trial (DAPIT) Study Group. Effect of pregnancy planning on maternal and neonatal outcomes in women with Type 1 diabetes,Diabet Med, 2017;34(9):1303-8.

[16] Moumhil N., Diabète et grossesse : à propos de 50 cas. Th D Med, pharm, Marrakech; 2013.

[17] Bouali M.,Pronstic maternel et foetal des grossesses chez des femmes diabétiques type 1, à propos de 39 cas. Th $\mathrm{D}$ Med, Tunis; 2008.

[18] Zeki R, Oats JJN, Wang AY, Li Z, Homer CSE, Sullivan EA., Cesarean section and diabetes during pregnancy: An NSW population study using the Robson classification,J ObstetGynaecol Res 2018;44(5):890-8.

[19] Owens LA, Sedar J, Carmody L, Dunne F. Comparing type 1 and type 2 diabetes in pregnancy- similar conditions or is a separate approach required? BMC Pregnancy Childbirth. 2015;15:69.

[20] Mirghani H, Begam M, Bekdache G, Khan F. Specialised fetal and maternal service: outcome of pre-gestational diabetes, $J$ ObstetGynaecol., 2012 Jul; 32(5): 426-9.

[21] Lepercq J, Le Ray C, Godefroy C, Pelage L, Dubois-Laforgue D, Timsit J., Determinants of a good perinatal outcome in 588 pregnancies in women with type 1 diabetes,Diabetes Metab., 2019;45(2):191-6.

[22] Li Y, Wang W, Zhang D., Maternal diabetes mellitus and risk of neonatal respiratory distress syndrome: a meta-analysis,Acta Diabetol, 2019: doi: 10.1007/500592-019-01327-4.

[23] Kawakita T, Bowers K, Hazrati S, Zhang C, Grewal J, Chen Z, et al. Increased Neonatal Respiratory Morbidity Associated with Gestational and Pregestational Diabetes: A Retrospective Study,Am $J$ Perinatol,2017;34(11):1160-8.

[24] Stanescu A, Stoicescu SM., Neonatal hypoglycemia screening in newborns from diabetic mothers--arguments and controversies, J Med Life, 2014;7(Spec No. 3):51-2. 